AÜIFD Cilt XLIV (2003) Sayı 2 s. 367-373

\title{
'Cumhuriyetin 80. Yılında Türk Ailesi' Paneli
}

\section{İhsan ÇAPCIOĞLU}

Ar. Gör., Ankara Üniversitesi İlahiyat Fakültesi

e-mail: icapci@divinity.ankara.edu.tr

Başbakanlık Aile Araştırma Kurumu'nun düzenlediği "Cumhuriyetin 80. Yılında Türk Ailesi" konulu panel 22 Ekim 2003 tarihinde Vakıflar Bankası Genel Müdürlüğü Toplantı Salonunda yapıldı. Panelin açılış konuşmasını Aile Araştırma Kurumu Başkan Vekili Nesrin Afşar Çelik yaptı. Çelik konuşmasında, tarih boyunca ailenin toplumsal değişmenin hem nesnesi hem de öznesi olduğunu vurgulayarak, ailenin bu pozisyonunun bütün toplumların tarihinde ona başat bir kurum olma özelliği kazandırdığını ifade etti. Bu bağlamda M. Kemal Atatürk'ün 'İçtimai Hayatın Temeli Aile Hayatıdır" sözünü hatırlatan Çelik, Atatürk'ün aileyi milli kültürümüzün temel unsuru olarak gördügüunü ve onun kurduğu Cumhuriyetin getirdiği çağdaş ilkelere göre şekillenen modern Türk Ailesinin Anayasanın 41. maddesi (Aile Türk Toplumun Temelidir) ile güvence altına alındığını 
belirtti. Vekalet ettiği Aile Araştırma Kurumu hakkında da bilgiler veren Nesrin Afşar Çelik, Aile Araştırma Kurumu'nun "aile ile ilgili milli politikalar üretmek" amacıyla Başbakanlığa bağlı bir birim olarak 1989 yılında kurulduğunu ve o tarihten günümüze kadar düzenlediği üç aile şûrası, pek çok konferans ve panelin yanı sıra, yirmi ayrı araştırma projesi, yüzü aşkın kitap, dergi, yüzlerce broşür ve matbu metinleri kamuoyunun istifadesine sunarak kamu yayıncılığı konusunda farklı bir hizmet alanı oluşturduğunu kaydetti. Ayrıca Çelik, kurumun aile alanında geniş bir veri tabanı oluşturmayı hedefleyerek ülkemizde aileyi kuşatan sorunlara yönelik çözümler sunduğunu ve böylece aile merkezli politikaların üretilmesine ciddi katkılar sağladığını ifade etti.

Panelin davetlileri arasında yer alan kadın ve aileden sorumlu devlet bakanı Güldal Akşit, ekonomik birlikteliklerin siyasi birlikteliklerle güçlendirildiği günümüz dünyasında son yıllarda giderek hız kazanan küreselleşme sürecinin bütün kurumlar gibi aile kurumunu da derinden etkilediğini ve 1950'lerden itibaren köyden kente göç hareketlerinin hızlandırdığı sanayileşme ve kentleşme olgusunun ortaya çıkardığı şartların aile yapımız üzerindeki etkilerin temel belirleyicileri olduğunu ifade etti. Akşit, son yıllarda bu iki olgunun etkisinin özellikle iktisadi ve sosyal şartlar üzerinde görüldüğünü ve eğitimi sürdürememe, yetersiz beslenme, mesken ve sağlık sorunu gibi problemlerin ailenin yaşam kalitesini düşürerek özellikle gençler arasında suça yönelme ve madde kullanımının artmasına yol açtığını belirtti. Bu tür sorunlar karşısında aileyi korumak için çeşitli sistemler geliştirildiğini sözlerine ekleyen devlet bakanı Akşit, bakanlık olarak küresel pazarlama ve reklam endüstrisi karşısında çaresiz kalan ailelerin parçalanmasını önlemek amacıyla sosyal destek projeleri hazırladıklarını ve Dünya Bankası ile Sosyal Yardımlaşma ve Dayanışmayı Teşvik Fonu tarafından ortaklaşa yürütülen 500 milyon dolarlık Sosyal Riski Azaltma Projesi çerçevesinde Dünya Bankasından finansal destek sözü aldıklarını ifade etti.

Panelin başkanı ve aynı zamanda ilk konuşmacısı sıfatıyla söz alan Gazi Üniversitesi Öğretim Üyesi Prof. Dr. Kadir Arıcı'nın konu başlı̆̆ı Sosyal Riskler Karşısında Ailenin Önemi idi. "Türk ailesi son otuz yıldır yaşadığımız değişimler karşısında sanki yeni bir İstiklal Savaşı veriyor" diyerek sözlerine başlayan Arıcı, aileyi tehdit eden sosyal riskleri hastalık, sağlık ve yaşlılık gibi fizyolojik riskler ve ölüm, işsizlik, konut, evlenme, çocuk sahibi olma gibi sosyo-ekonomik riskler olmak üzere iki gruba ayırdı. Toplumu sürekli tehdit altında tutan bu risklerle mücadelenin insanlık tarihi kadar eski olduğunu vurgulayan Arıcı, modern sosyal güvenlik sisteminin geleneksel güvenlik anlayışından farklı olduğunu, bugün artık risk ortaya çıkmadan gerekli tedbirlerin alınmasına yönelik bir güvenlik sisteminin geliştirildiğini, oysa geleneksel güvenlik anlayışının ancak risk ortaya çıktığında aileye el uzattığını ifade etti. Türk toplumu gibi güçlü aile bağlarına sahip toplumlarda sosyal riskler karşısında ailenin korunmasının 
gerekliliği üzerinde de duran Prof. Dr. Kadir Arıcı, günümüzde sadece aileyi değil, aynı zamanda akraba ve yakınları da kapsayan bir sosyal güvenlik sisteminin câri olduğunu sözlerine ekledi. "Sosyal riskler karşısında aileye gerekli destek mutlaka verilmelidir" diyen Arıcı, bu desteğin sistemli bir devlet politikası haline getirilmesi gerektiğini belirtti. Ailenin öncelikle geleneksel değerleri ve kültürü gelecek kuşaklara aktarma konusunda gereken özeni göstermesi gerektiğini sık sık vurgulayan Prof. Arıcı, bu konuda devletin aileye destek sağlayabileceğini, Türkiye Cumhuriyeti Devleti'nin sosyal yardım için ihtiyaç duyulan yeterli kaynağa sahip olduğunu, ancak asıl problemin bu kaynağın nasıl kullanılacağı konusunda yaşandığını kaydetti. Yoksullukla mücadelenin devletin öncelikli görevi olduğuna dikkat çeken Arıcı, "devlet yoksullukla mücadele etmek istiyorsa çok iyi işleyen sosyal yardım ve destek birimleri kurmak zorundadır. Aileyi koruma konusunda sosyal yardım ve destek sağlama, artık devletin başlıca görevleri arasına girmelidir. Devlet ülke çapında yardıma muhtaç aileleri tespit etmeli ve bu ailelere çağdaş usullerle yardım götürmelidir. Böylece gerçekten ihtiyacı olan, fakat bunu dile getirmeye çekinen ailelere yardım edilmiş ve medyada izlediğimiz çağdışı yardım görüntülerinin önüne geçilmiş olur" dedi. Prof. Arıcı bildirisini, "geleceğin güçlü Türk devletinin temelinde güçlü Türk ailesi yer alacaktır" diyerek noktaladı.

Panelin ikinci bildirisi Orta Doğu Teknik Üniversitesi Öğretim Üyesi Prof. Dr. Olcay İmamoğlu tarafından sunuldu. İmamoğlu konuşmasına, panel duyurusunda Aile İ̧̧i İletişim Sorunları olarak belirlenen bildiri başlığını, hazırlık sürecinde konunun sınırlandırılmasına duyulan ihtiyaçtan dolayı, Aile Ortamında Benlik Kurguları ve İletişim Yönelimleri olarak değiştirdiğini belirterek başladı. İmamoğlu devamla şunları söyledi: "İletişim yönelimlerinin kaynağında belirli zihniyet örüntüleri yatar. Çoğu zaman dış dünyayı (realiteyi) olduğu gibi algıladığımızı zannederiz. Oysa biz gerçeği içinde bulunduğumuz zihinsel koşullara göre algılarız. İnsan olarak temel sorunlarımızdan birisi, anlamlandırma sorunudur. Yaşamla ilgili çeşitli anlamlar geliştirmek zorundayız. Bunu yapabilmek için ise, içinde bulunduğumuz kültürel ortamın bize sunduğu malzemeden yararlanırız. Kültür, en genel tanımıyla, anlam örüntüleri üzerine kurulur. Anlam örüntüleri çeşitli zihniyet örüntüleri ile ilişkilidir. Bireyin ve toplumun sahip olduğu zihniyet örüntüleri ise, nasıl bir hayat yaşadığımızı belirler. Bir süre sonra dünyayı kendi penceremizden görmeye başlarız". Bu noktada kültüre uygun benlik gelişiminin bireyin sosyalleşme sürecinde elde ettiği kazanımlardan olduğuna işaret eden İmamoğlu, aile, okul, arkadaş çevresi, medya ve diğer çevresel etkilerin bireyin benlik sistemi üzerinde belirleyici rol oynadığını ifade etti. Prof. Dr. Olcay İmamoğlu'na göre, ben nasıl biriyim?, nasıl birisi olabilirim? ve nasıl olmalıyım? gibi benlik sistemimizin bize yönelttiği sorular, bireyi kuşatan kültürel sistem içinde insan nasıl olmalı? sorusunda ifadesini bulmakta ve böylece kültüre uygun benlik gelişim süreci başlamış olmaktadır. İmamoğlu, bu bildiriyi 
hazırlarken ulaşmak istediği nihai amacın 'batı kültürüyle doğu kültürünün farklı birey tanımlarından hareketle çağdaş Türk toplumunun nasıl bir aile modeline sahip olduğunu tespit etmek ve Batıdaki aile modeliyle karşılaştırmalar yaparak Türk toplumunun aile yapısını tanımlayacak bir model ortaya çıkarmak' olduğunu vurguladı. Batı kültüründe 'birey olmak' çok önemli görüldüğü halde, özellikle 1970'lerden sonra bireyci benlik anlayışının sorgulanmaya başlandığını ve bu konuda toplumsal cinsiyetle ilgili araştırmaların etkili olduğunu kaydeden İmamoğlu, batının benlik modelinin bütün toplumlar için geçerli bir model olmadığının zamanla anlaşıldığına dikkat çekti. Ülkemizdeki benlik anlayışının da batının benlik tanımına uymadığının altını çizen Olcay İmamoğlu, "Türk insanının benlik anlayışı hem bağımlı hem de ilişkili olma yönünde değişme gösteriyor" dedi. 'Bağımsız bir kişiliğe sahip olma' ile 'ilişkili (bağımlı) bir kişiliğe sahip olma' arasında literatürde varsayıldığı gibi birbirine karşıt bir ilişkinin olmadığını belirten İmamoğlu, bağımsız olma (ayrışma) ve bağımlı olma (bütünleşme) ilişkisinden hareketle Türk toplum yapısını yansıttığını düşündüğü bir aile modeli ("Dengeli Ayrışma-Bütünleşme Modeli") geliştirdiğini sözlerine ekledi. Prof. İmamoğlu'na göre, bireyci batı toplumlarında 'kişi gelişimini içsel dayanaklı olarak sürdürmelidir' deniyor. Kollektif doğu toplumlarında ise, 'birey dışsal dayanaklı olmalıdır' anlayışı hakim. Batı toplumları bireye dış ortama karşı daha mesafeli olması gerektiğini, doğu toplumları ise, mesafesizliği, dışa yakınlığı öğütlemektedir. Batı kültürü insanın düşünsel ve fiziksel ayrışmasını (kendileşme) önemsediği halde, doğu külttürü düşünsel ve zihinsel bütünleşmeye önem vermektedir. Son dönem Türk toplumunun aile yapısında her iki eğilimi (ayrışma-bütünleşme) de yansıtan yönlerin bulunduğunu kaydeden İmamoğlu, "Dengeli Ayrışma-Bütünleşme Modeli'nin" ön gördüğü insan tipinin Türk insanını karakterize ettiğini belirtti ve bu konuda örnekler vererek konuşmasını tamamladı.

Hacettepe Üniversitesi Öğretim Üyesi Prof. Dr. Günsel Terzioğlu, Aile ve Ekonomi başlıklı bildirisinde, günümüz Türk toplumunda ailenin sosyoekonomik yapısı ile ilgili bilgiler verdi. Sosyal yapı kadar sosyo-ekonomik yapının da temel kurumlarından birinin aile olduğuna dikkat çeken Terzioğlu, sosyo-ekonomik yapı değişimlerine bağlı olarak bugün ailenin; enflasyon, kredi bulunabilirliği, yatırım fırsatları ve gelir durumu gibi ekonomik faaliyetlerden etkilendiğini belirtti. Ailenin başlıca ekonomik faaliyetlerini gelir, harcama, tasarruf-yatırım ve borçlanma olmak üzere dört maddede toplayan Terzioğlu, "II. Dünya Savaşı'ndan önce ailenin gelirini sadece erkekler sağlıyordu. Savaş sonrası siyasi, sosyal ve iktisadi alanlardaki hızlı değişimlerin bir sonucu olarak kadınlar da işgücüne katılmaya başladı. Ancak, kadınların işgücüne katılım oranlarında son yıllarda düşüş görülmektedir. Oysa işgücüne katılan kadın ailenin ekonomik durumuna ciddi katkılar sağlamaktadır" dedi. Bugün Türkiye'de hane halklarının \% 43'ünün 'yoksul' olduğunu kaydeden Terzioğlu, ailenin gelir 
politikasına en az eğitim kadar önem verilmesi gerektiğini, zira ailenin gelir durumunun toplumun tüketim alışkanlıkları üzerinde doğrudan etkili olduğunu kaydetti. Aile giderleri içinde ilk iki sırayı konut ve gıda harcamalarının aldığını belirten Terzioğlu, son yıllarda konut harcamalarının gıda harcamalarının önüne geçtiğini; eğitimin en son sırada yer aldığını, bununla birlikte alkollü içecek harcamalarının eğitime yapılan harcamaların üç katına yaklaştığını ifade etti. Ailenin, yaşam kalitesinin temel belirleyicileri olan fiziksel ve ruhsal gereksinimleri karşılamakta zorlandığını sıkça vurgulayan Terzioğlu, tasarruf eğilimi ve hacminin giderek düştüğünü, Devlet İstatistik Enstitüsü verilerine göre hane halklarının sadece \% 16'sının tasarruf yapabildiğini ve tasarruf adı altında yapılan yatırımların ekonomik açıdan yatırım olarak kabul edilmeyen altın ve döviz gibi alanlarda yoğunlaştığını belirtti. Ülkemizin içinde bulunduğu ekonomik kriz ortamında ailelerin çeşitli borçlanma yolları aramaya başladığını kaydeden Prof. Terzioğlu, "hane halklarının çoğu biriken borçlarını ödeyebilmek için borçlanmaktadır. Akraba ve yakınlardan yeterli desteği sağlayamayan aileler, tüketici kredisi ve kredi kartları aracılığıyla bankalara borçlanmaktadır. Banka kredileri satın alma arzusunu ve gücünün üzerinde borçlanma eğilimini arttırmaktadır. Nakit para taşıma yerine harcama kolaylığı sağlamak için geliştirilen kredi kartları ödeme güçlüğü çeken ailenin ekonomik durumunu daha da kötüleştirmektedir" dedi. Aile değerlerinin topluma aşılanması için politikalar geliştirilmesinin önemi üzerinde de duran Terzioğlu, ailelerin eğitimsizlik yüzünden medyanın oluşturmaya çalıştığı imajlardan etkilendiğini ve 1980'lerden bu tarafa üretilen sosyo-ekonomik politikaların aile değerlerinde yozlaşmalara yol açtığını sözlerine ekledi. Terzioğlu bildirisinin sonunda şu önerilerde bulundu: Devlet, istihdam, gelir dağılımı, yatırım fırsatları ve borçlanma gibi konularda politikalarını yeniden gözden geçirmeli ve sosyo-ekonomik açıdan aileye destek olmalıdır. Ayrıca, ailelerin ekonomik ve sosyal değişimlere uyum sağlamaları ve bu değişimlerle mücadele edebilmeleri için toplumdaki makro ekonomik eğilimleri anlama; para ve zaman gibi ekonomik kaynakların idaresi, enflasyonla mücadele gibi konularda bilgilendirilmesi amacıyla örgün ve yaygın eğitimin kapsamı genişletilmelidir.

Panelin dördüncü konuşmacısı Halkla İlişkiler Uzmanı İkbal Gürpınar'dı. Medya ve Aile başlıklı bildirisinde, bireylerin ve toplumların mutluluğu için etik, eğitim ve ekonominin gerekliliği üzerinde duran Gürpınar, ekonominin son zamanlarda etik ve eğitimin önüne geçtiğine dikkat çekerek medyadan konu ile ilgili örnekler verdi. Medyadaki bazı programların aileyi ekonomik anlamda lüks tüketime ve toplumsal değerler alanında ahlaki dejenerasyona sürüklediğine de işaret eden Gürpınar, özetle şunları söyledi: "Medyada izlediğimiz, fakat beğenmediğimiz ve onaylamadığımız programlar karşısında tepkimizi demokratik yollardan mutlaka dile getirmeliyiz. Medyanın bize sunduğu her şeyi olduğu gibi kabul etmemeliyiz. Çünkü bugün medyada izlediğimiz bazı programlar, Türk 
toplumunun ahlaki değerleri üzerinde son derece zararlı sonuçlar doğuruyor. $\mathrm{Bu}$ alandaki denetimsizliğin önüne geçilmezse pek çok ailevi ve toplumsal değerlerimizi kaybedebiliriz".

Panelin son konuşmacısı Türkiye Göç Araştırmaları Ağı Koordinatörü Dr. Serim Timur, Sosyo-Kültürel Değişim Süreci ve Aile başlıklı bir bildiri sundu. 1960'lı yıllardan günümüze, değişen Türk aile yapısı hakkında bilgiler veren Timur, Türkiye'de ailelerin büyük çoğunluğunun zaman içinde çekirdek aileye dönüştügünü kaydetti. Kırsal kesimde geniş ailenin temel dayanağının mülkiyet olduğunu belirten Timur, topraksız tarım iş̧̧ileri arasında çekirdek aile oranının 1968'de \% 50'ler civarında iken bugün bu oranın \% 80'lere ulaştığına dikkat çekti. Kırsal bölgelerdeki aileler arasında çekirdek aile oranındaki bu artışın göç hadisesinin somut göstergelerinden biri olduğuna işaret eden Serim Timur, evlenmiş oğul ve kızların aileden göç yoluyla ayrıldığını ve böylece daha çok büyük kentlerin aile modelini karakterize eden çekirdek ailenin oranında kırsal kesimde de hızlı bir artış yaşandığını ifade etti. Ülkemizde son yıllarda ataerkil ve geniş aile tipinde genel anlamda bir azalma görülmesine rağmen, yoksul gecekondu bölgelerinde ekonomik kriz ortamından dolayı yeniden geniş aileye dönüş yaşandığına dikkat çeken Timur, ailenin sosyal güvenlik ve dayanışma sağlayıcı rolüne vurgu yaptı. Türk ailesinin oluşumu hakkında da bilgiler veren Timur, Türkiye'de evli çiftlerin yaklaşık üçte birinin birbirleriyle akraba ve akraba olan eşlerin \% 80'inin kardeş çocukları olduğunu, özellikle erkek kardeş çocuklarının birbiriyle evlendiklerini belirtti. Timur özetle şunları söyledi: "Akraba olan eşlerin oranı Ankara, İstanbul ve Izmir'de \% 17 iken, diğer kentlerde \% 19'a, köylerde \% 36'ya çıkmaktadır. Kocası akraba olan kadınların \% 29'u amcalarının oğlu, \% 49'u dayı, hala ya da teyze oğlu olmak üzere kuzenleriyle evlenmişlerdir. İkinci kuşak kuzenler arası yani kardeş torunlarının birbiriyle evlenme oranı \% 5'dir. Bunların dışında kalan akraba evliliklerinin, diğer uzak akrabalar arasında yarı yarıya dağıldıkları görülmektedir. Akrabalar arası evliliği, geniş ve ataerkil aile biçimleri pekiştirmektedir. Akrabası ile evli olanların oranı, kuruluştan beri çekirdek aile olan ailelerde \% 20 iken, ataerkil geniş ailelerde \% 34'e çıkmaktadır. Köylerde bütün aile biçimlerinde akraba evliliği diğer yerleşim yerlerinden daha yüksektir. Bölgeler arası değerlendirmede en düşük oran \% 20 ile Batı Anadolu'da, en yüksek oran ise \% 37 ile Doğu Anadolu'dadır. Ancak Batı Anadolu'da da ataerkil ailelerde çekirdek ailelere göre oranın yükssek olduğu görülmektedir". Serim Timur, günümüz Türk ailesinin sosyoekonomik yapısı ile ilgili olarak daha gerçekçi ve politika yönelimli araştırmalara ihtiyaç duyulduğunu belirterek konuşmasını tamamladı.

Cumhuriyetimizin 80. Yılı kutlamaları çerçevesinde Başbakanlık Aile Araştırma Kurumu Başkanlığı tarafından düzenlenen panel, konusunun güncelliği ve konuşmacı olarak seçilen uzmanların günümüz Türk ailesini kuşatan sorunlar karşısında sundukları politika önerilerini yansıtması açısından oldukça başarılıydı. Prof. Dr. Kadir Arıcı ve İkbal Gürpınar hariç, 
diğer konuşmacıların sunuşlarını görsel malzeme ile zenginleştirmeleri, izleyenlere aktif dinleme imkanı sağladı. Bütün panelistler ailenin sosyal riskler karşısında korunması için örgütlenmenin ve bilinçlenmenin önemi üzerinde durdu. Bu anlamda özellikle Kadir Arıcı'nın bildirisi, aileye sunulacak sosyal desteğin düzenli ve iyi işleyen bir devlet politikası haline getirilmesi gerektiğini vurgulaması açısından kayda değerdi. Hızlı sosyal, siyasal, ekonomik ve yapısal değişimlerin tüm toplumsal kurumlar gibi aile kurumunu da etkilediği ve özellikle yaşanan ekonomik krizlere bağlı olarak aile yapısının daraldığı, aileler arası gelir dağılımındaki dengesizlikten kaynaklanan açığın büyüdüğü ve enflasyonun ailenin yaşam kalitesini düşürerek yoksulluğu körüklediği ülkemiz koşullarında aileyi kuşatan ekonomik sorunlara sıkça temas edilmesi panelin dikkat çeken yönleri arasındaydı. Bu çerçevede özellikle, yoksullaşmanın, ailenin toplumsal konumunu, rolünü, aile bütçelerini, işgücüne katılım biçimlerini, ev içi sorumlulukların dağılımını, ailenin varlık durumunu, toplumsal çevre ile ilişkilerini ve toplumsal yaşama katılım eğilimlerini etkilediği ifade edildi. Sonuç olarak, Cumhuriyetimizin 80. Yılında Türk Ailesinin geçirdiği değişim ve dönüşümü bir ölçüde ortaya koymaya çalışan bu paneli düzenleyen Aile Araştırma Kurumuna, değerli konuşmacılara ve katılımcılara teşekkür ediyor, bundan sonra da bu alanda var olan problemlerin çözümüne yönelik olarak bu gibi etkinliklerin yoğun bir şekilde yapılmasını temenni ediyoruz. 